Article

\title{
Radioactivity in Oily Sludge and Produced Waste Water from Oil: Environmental Concerns and Potential Remedial Measures
}

\section{Avin E. Pillay ${ }^{1, *}$, Fadhil M. Salih ${ }^{2}$ and Muthana I. Maleek ${ }^{3}$}

1 Chemistry Department, The Petroleum Institute, P.O. Box 2533, Abu Dhabi, UAE

2 C/o Department of Clinical and Biomedical Physics, College of Medicine and Health Sciences, Sultan Qaboos University, P.O. Box 35, Al Khoud, 123, Oman; E-Mail: fadhilsalih@gmail.com

3 Department of Biology, College of Science, University of Wasit, Kut, Wasit, 4256, Iraq; E-Mail: muthana.ibrahem@yahoo.com

* Author to whom correspondence should be addressed; E-Mail: apillay@pi.ac.ae; Tel.: +9712-6075417; Fax: +9712-6075423.

Received: 21 January 2010; in revised form: 18 March 2010 / Accepted: 24 March 2010 / Published: 31 March 2010

\begin{abstract}
Produced water separated from oil is usually returned to the environment and could permeate through the water table. If such water is contaminated with radioactive substances, it could create a definite threat to the water supply, especially in arid regions where ground water and overhead streams are sources of potable water. Low-level radioactive contamination of oily sludge is equally hazardous and also leads to detrimental pollution of water resources. We investigated the distribution of ${ }^{226} \mathrm{Ra},{ }^{40} \mathrm{~K}$ and ${ }^{228} \mathrm{Ac}$ in produced waste water and oily sludge and found abnormal levels of radioactivity. A total of 90 ground wastewater samples were collected from different sites for a period of one year. The presence of these radionuclides was identified by their characteristic gamma rays. The detection system consisted of a high-purity germanium detector. Our results show that about $20 \%$ of the samples exhibited $20-60 \mathrm{~Bq} / \mathrm{L}$ radioactivity and $\sim 6 \%$ of the samples exceeded $60 \mathrm{~Bq} / \mathrm{L}$. Roughly $70 \%$ of the experimental samples fell in the range of $2-20 \mathrm{~Bq} / \mathrm{L}$, which still exceeded the maximum admissible drinking-water limit $0.2 \mathrm{~Bq} / \mathrm{L}$.
\end{abstract}

Keywords: radioactivity; oil sludge; waste water; gamma rays 


\section{Introduction}

In desert regions water is precious, and the demand for good quality water is rapidly increasing. Most areas rely heavily on overhead streams and underground supplies to feed livestock and for domestic purposes [1]. The oil processing industry discharges considerable volumes of waste water daily. Produced waste water is the aqueous component separated from oil. This aqueous phase is in contact not only with the oil but also with the sludge that is associated with the oil. As a result, various components of the ecosystem could be affected leading to undesirable pollution. Waste water extracted from oil is usually chemically treated and returned to the environment, thus it is one of the most significant sources of ground water pollution, especially if it has elevated levels of natural radioactivity [2-10]. If waste water disposed of in the environment finds its way into aquifers (Figure 1), it could pollute the water table. Groundwater movement is generally very slow compared to movement of surface water, and usually travels less than 100 feet a year [2]. Because of this, the radioactivity could concentrate in slow moving water bodies and persist for many years, eventually posing a lethal threat to the ecosystem. This threat to sustainable development is therefore our primary concern. The maximum permissible level of radioactivity in drinking water is $0.2 \mathrm{~Bq} / \mathrm{L}$ [11]. Some of our experimental samples contained radioactive levels in 20-60 Bq/L, while others were even higher-up to $100 \mathrm{~Bq} / \mathrm{L}$. Since ground water is vital for both human consumption in arid countries [9,10] and irrigation and industrial purposes [12], it is essential to protect groundwater sources in desert regions. It should be underscored that when the waste water is dumped, it invariably seeps through the soil and gradually contaminates the water table and shallow groundwater $[3,4]$. Hence, if we know beforehand the level of radioactivity of the dumped water, the potential hazard can be conveniently assessed and averted. This is relatively cost-effective as regular groundwater is usually monitored by drilling wells and analyzing samples from the wells for contaminants. It is thus imperative to be able to detect the changes in natural systems resulting from such pollution. Our primary objectives, therefore, were to: (i) evaluate the potential impact of radioactive contamination on the environment; and (ii) suggest possible procedures for remediation.

\section{Results and Discussion}

\subsection{Radium in Waste Water from Oil}

${ }^{226} \mathrm{Ra}$ originates from ${ }^{238} \mathrm{U}$ and decays to ${ }^{222} \mathrm{Rn}$ [13-15]. It is an alpha and gamma emitter, with a half-life of roughly 1,600 years. Exposure to elevated alpha and gamma radiation creates serious biological problems, especially genetic damage, which usually arises from exposure to low doses over an extended period [15]. Bioaccumulation of ${ }^{226} \mathrm{Ra}$ in the food chain is a likely potential hazard and the protection of the ecosystem from such threat is of prime concern $[5-10,14,15]$. The human body treats radium in a similar way that it metabolizes calcium. Oral ingestion of minute quantities of radium results in its accumulation in the bones and produces serious damage. Ultimately, the damage from continuous internal exposure to radium can potentially cause bone and sinus cancer. Bone tumors are the most common followed by tumors in the nasal mucosa. 
Figure 1. Flow diagram showing the path of underground water through the ecosystem.

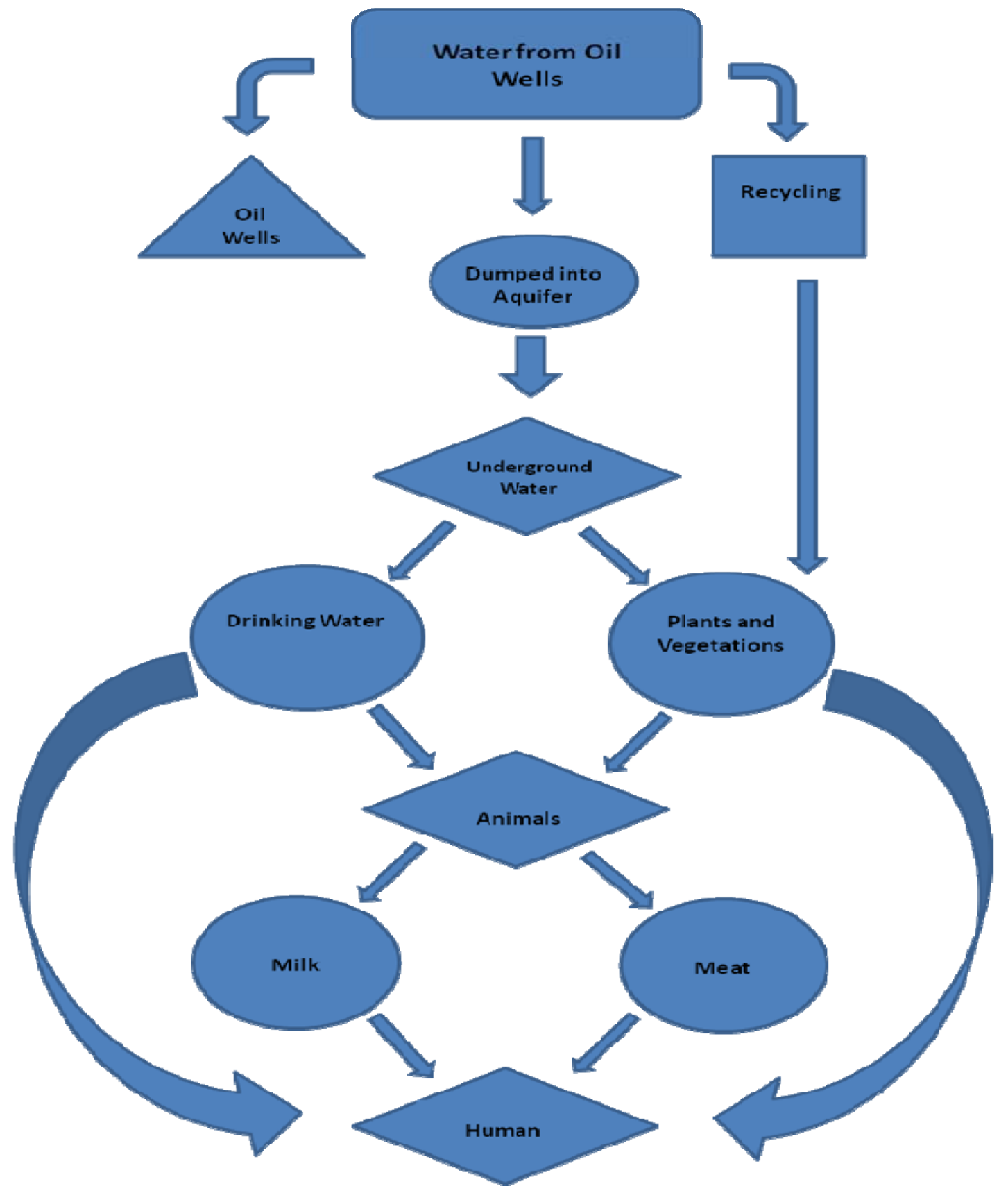

The distribution of ${ }^{226} \mathrm{Ra}$ for the one-year period is shown in Figure 2. As can be seen from our results, the levels in produced water vastly exceeded the drinking water limit $(0.2 \mathrm{~Bq} / \mathrm{L})$ in several cases. Such activities could affect the biosphere when the produced water is returned to the environment. A closer inspection of Figure 2 tells us that although there is a considerable spread of the data, more than $95 \%$ of the results exceeded the permissible requirement.

A breakdown of the results shows that about $30 \%$ of the samples fell below $20 \mathrm{~Bq} / \mathrm{L}$; roughly $50 \%$ were in the range $20-60 \mathrm{~Bq} / \mathrm{L}$ and about $20 \%$ were in $60-100 \mathrm{~Bq} / \mathrm{L}$. It must be remembered that oil is pumped from thousands of feet underground. Therefore, the source of the radium originates from possible desorption of rock material and radioactive decay from minerals [4]. Suitable protective measures should, therefore, be put in place to shield the environment from such radiation. 
Figure 2. Distribution of ${ }^{226} \mathrm{Ra}$ in waste water from oil.

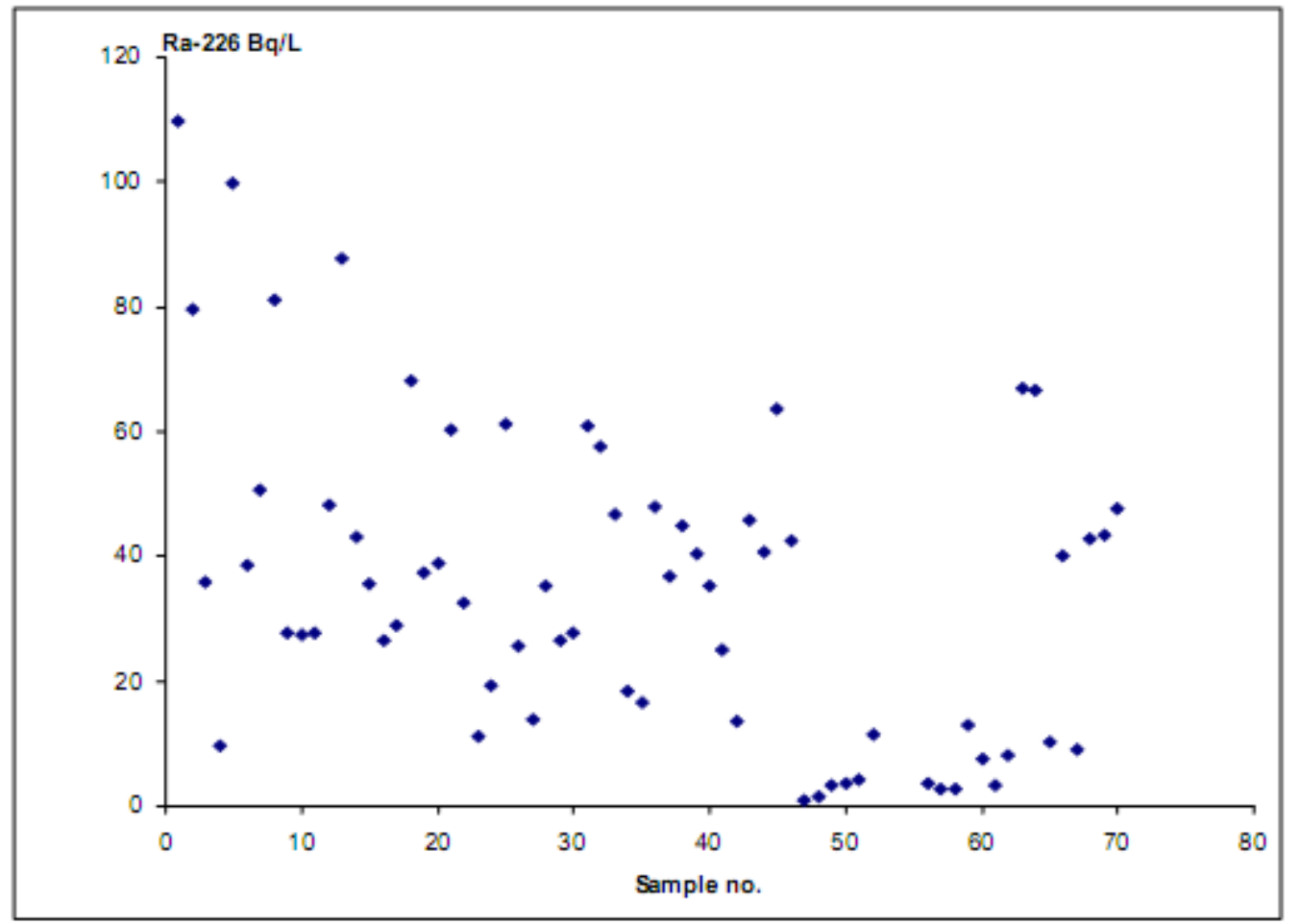

\section{2. ${ }^{40} \mathrm{~K}$ in Produced Waste Water}

${ }^{40} \mathrm{~K}$ contamination could originate from constant attrition of the earth's crust that contains natural radioactive materials [3,4]. Potassium-40 is a naturally occurring radioactive isotope of potassium [5-10]. It represents $0.012 \%$ of naturally occurring potassium, and its concentration in the earth's crust is about $1.8 \mathrm{mg} / \mathrm{kg}$, or $0.5 \mathrm{~Bq} / \mathrm{g}$. The half-life of ${ }^{40} \mathrm{~K}$ is 1.3 billion years, and it undergoes forked-decay to ${ }^{40} \mathrm{Ca}$ by emitting a beta particle and to ${ }^{40} \mathrm{Ar}$ by electron capture with emission of an energetic gamma ray [6,13]. It behaves in the environment in the same way as other potassium isotopes, being assimilated into the tissues of all plants and animals through normal biological processes. Therefore, abnormal levels of ${ }^{40} \mathrm{~K}$ in produced water can be detrimental to the biosphere.

The distribution of ${ }^{40} \mathrm{~K}$ from the samples of interest appears in Figure 3, where we observe that over the one-year monitoring period the levels of radioactivity varied widely. The reason for the wide variation is unclear, but this distribution could be useful as a database for radiation workers in this area. As can be seen from the results (Figure 3) about 20\% of the samples fell between 20 and $60 \mathrm{~Bq} / \mathrm{L}$ and about $6 \%$ exceeded $60 \mathrm{~Bq} / \mathrm{L}$. Roughly $70 \%$ of the experimental samples fell between 2 and 20 $\mathrm{Bq} / \mathrm{L}$, which still exceeded the maximum admissible drinking-water limit of $0.2 \mathrm{~Bq} / \mathrm{L}$. The elevated levels of this radioisotope could serve as an indication of potential pervasive radioactive contamination of the water table [2], and could also potentially affect overhead streams and other aquatic resources when the wastewater is disposed. 
Figure 3. Distribution of ${ }^{40} \mathrm{~K}$ in waste water from oil.

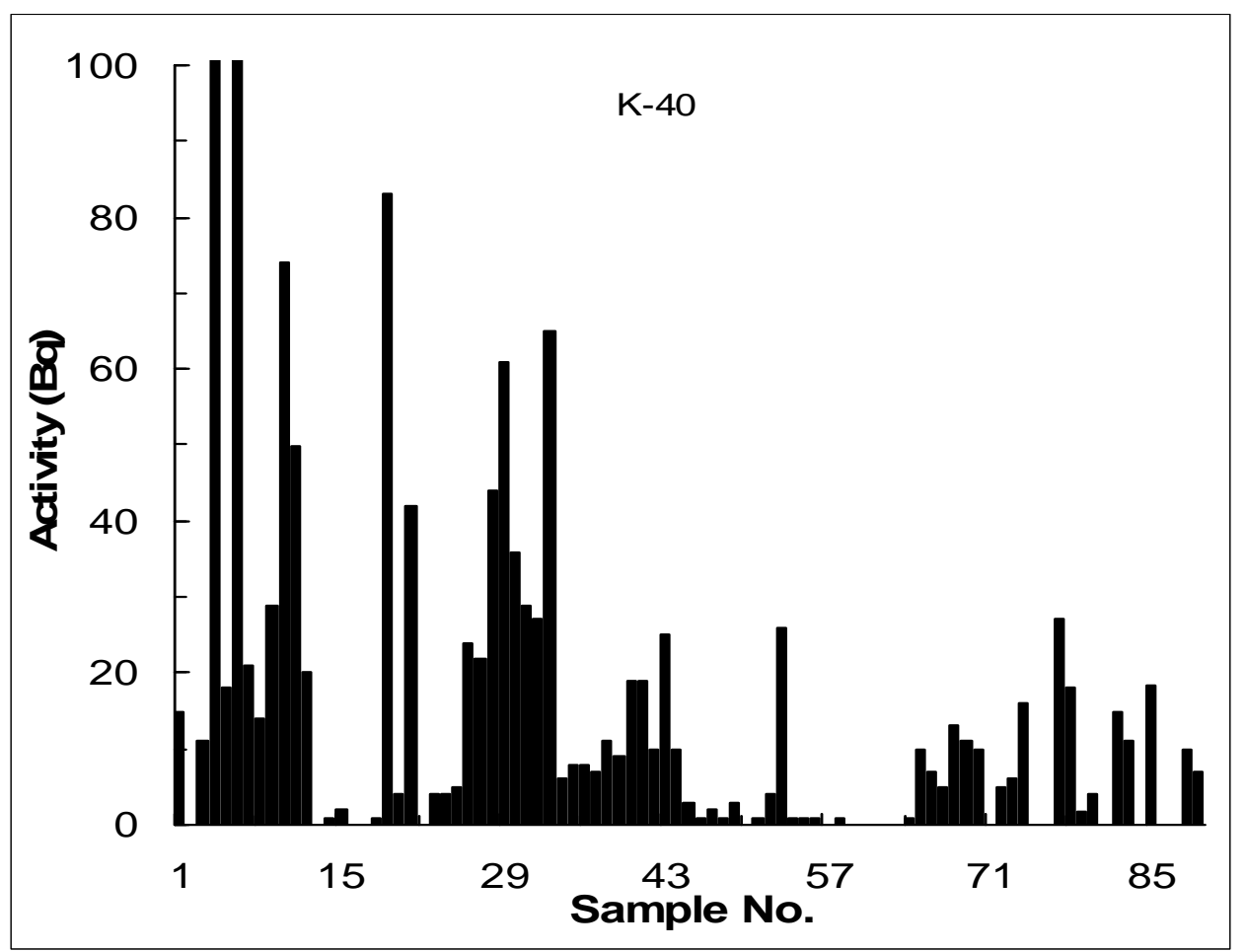

\subsection{Actinium in Oily Sludge}

${ }^{228} \mathrm{Ac}$ is the daughter of ${ }^{228} \mathrm{Ra}$ that originates in the Thorium series [5-10]. The actinium is in secular equilibrium with the parent, and its presence at elevated levels in the environment constitutes a significant long-term health hazard because of the well-known toxicity of radioactive materials [7-10]. The elevated levels of this radioisotope could also be used as a useful indicator of the corresponding elevated presence of ${ }^{228} \mathrm{Ra}$ (Figure 4) [4]. The existence of ${ }^{228} \mathrm{Ac}$ in petroleum sludge is relatively underexplored. This investigation, therefore, could provide useful information for others who may be interested in such research. A brief survey of the documented literature reveals that the "acceptable" level of ${ }^{228} \mathrm{Ac}$ in soil and regular sludge is roughly $60 \mathrm{~Bq} / \mathrm{kg}[14,15]$. We obtained values up to $600 \mathrm{~Bq} / \mathrm{kg}$ — ten times higher.

Figure 4. Decay scheme of ${ }^{228} \mathrm{Ac}$.

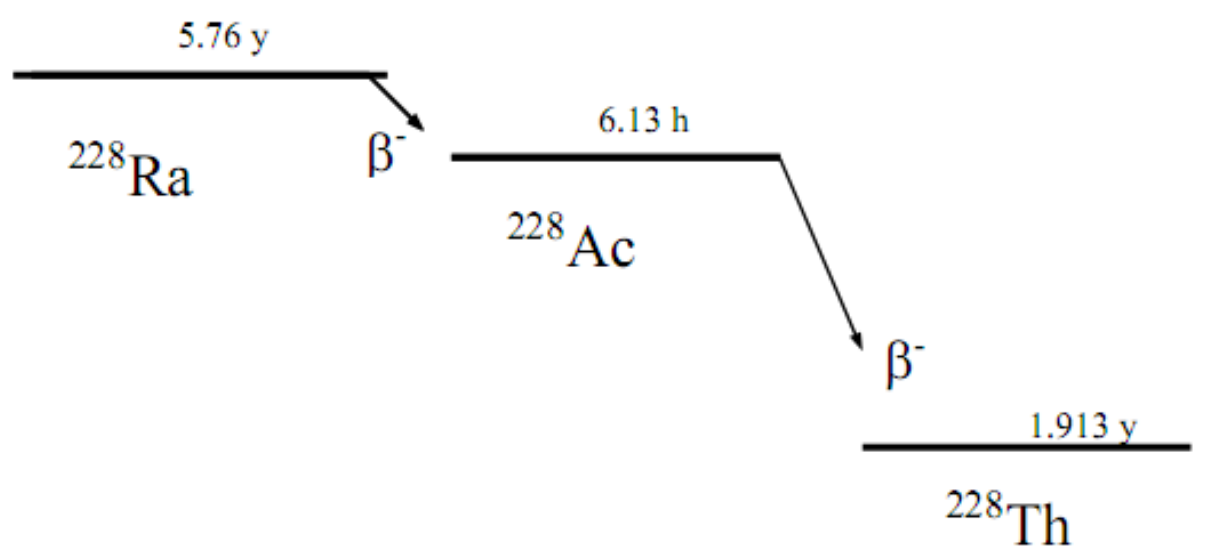


This led us to infer that our actinium levels were elevated, and that such undesirable contamination of the sludge called for application of appropriate remedial measures. An inspection of our results (Figure 5) indicates that about $40 \%$ of the samples exceeded the "acceptable" value of $60 \mathrm{~Bq} / \mathrm{kg}$, and in some cases the levels were much higher. The distribution over the one-year monitoring period (Figure 5) revealed that the data do not follow a particular trend. Here again, the reason for this variation is not clear, but the distribution shown could serve as a rough guideline of actinium levels in oily sludge. A point to note is that the elevated activities encountered in this study could affect aquatic resources when the sludge is sometimes used as a sand replacement in construction material or on sludge farms. Our study, therefore, could make a useful contribution to ongoing sustainable development in the region, because the contaminated sludge could indirectly contaminate water supplies through agricultural run-off and rain-water permeation of the water table.

Figure 5. Distribution of ${ }^{228}$ Ac in oily sludge.

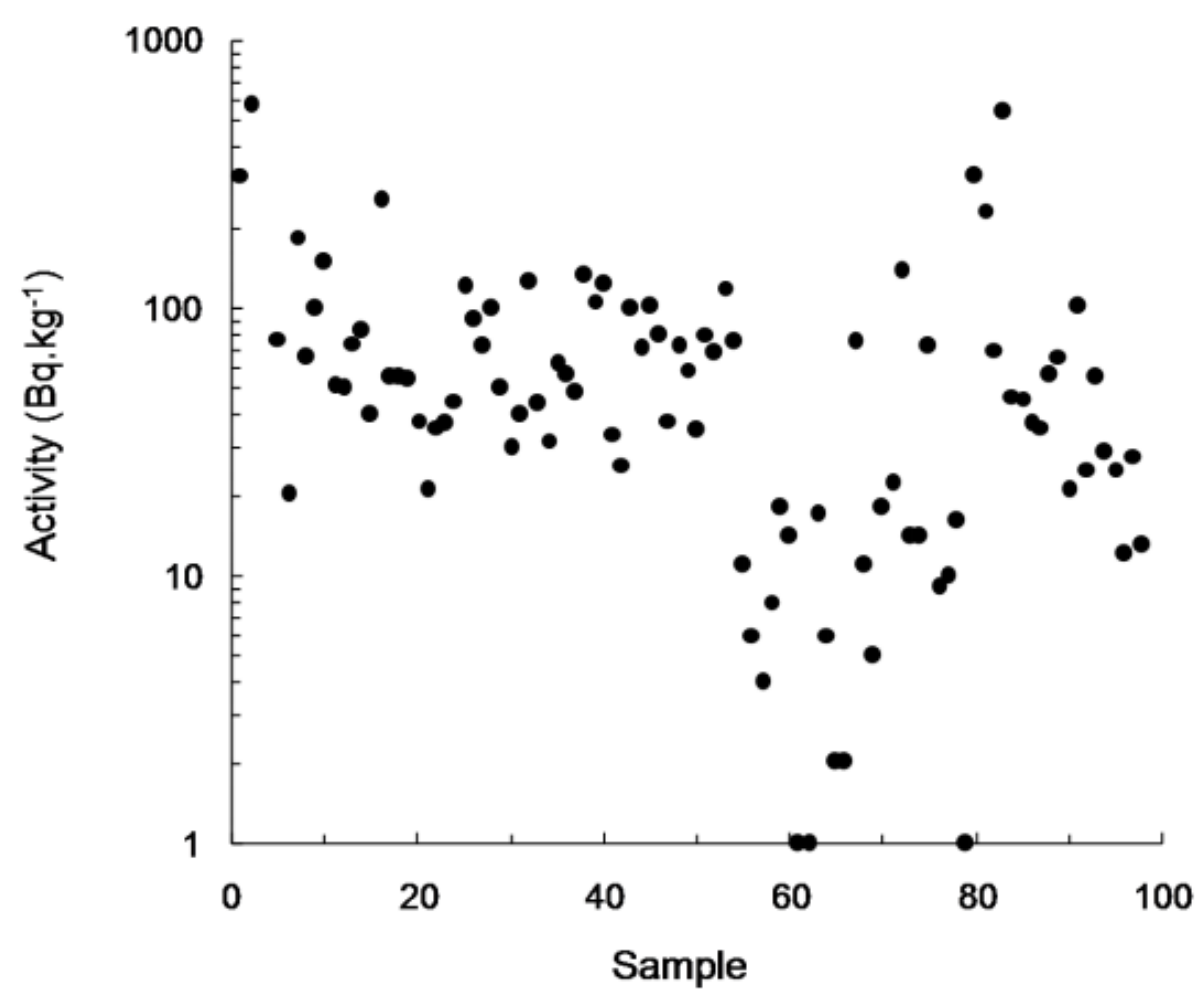

\subsection{Environmental Concerns/Potential Remedial Measures}

The study is an obvious source of interest because it can be linked to sustainable living. Of significance is that our research delineated the potential environmental impact in the region because radioactivity from produced waste water and sludge (at levels $>0.2 \mathrm{~Bq} / \mathrm{L}$ ) could lead to a wide contamination of water supplies. Shearman has shown that sustainable development is centered on human needs [16]. Robinson has extended this description and states that environmental sustainability essentially seeks to improve human welfare by protecting resources used for human needs [17]. It has been shown [1] that dumped waste water, like rainwater, infiltrates the water table, and could pollute potable streams and underground aquatic resources. Hence, the general impact on the environment is a cause for concern, and our work could make a useful contribution to the ongoing sustainable 
development in the region. Essentially, the overall potential impact is primarily the effect on public health, livestock and crops; and secondly the effect on wildlife such as rare birds and animals [18]. Let us consider these aspects in more detail.

(i) Percolation of the water table by rainwater, irrigation and dumping of waste water has been previously studied [19]. The potential contamination of local water bodies (such as streams, rivers and underground supplies) from such infiltration can become a serious problem, especially if the radioactive levels are elevated. A remedial measure to inform the community of general pollution is already in place; and because of an increasing awareness to possible environmental contamination, the impact of the pollution on the general community has been minimized [20]. As a result, the water in overhead streams near villages is not as widely used for drinking purposes, but mainly for cleaning clothes, utensils and certain consumables such as vegetables. These activities can be further reduced as more environmental studies are conducted in the area, and more environmental awareness is disseminated among the community [20]. The impact on livestock and crops is more complex. Goats and cattle consume the water at some sites, and could subsequently propagate the pollution to mankind.

(ii) The resultant impact of elevated radioactive bioaccumulation is another matter for consideration. Such accumulation could have an unfavourable effect on the biosphere [19]. Therefore, excess bioaccumulation of radioactivity in the food chain (for example) is a potential hazard and deserves further investigation. Of interest is that the deleterious effect on plants is often underrated; but radioactive toxicity in plants can be quite severe, leading to serious disorders [7-9]. Bear in mind that natural conservation is attracting global interest and any such contamination can pose a significant threat. These particular problems can be curbed by searching for solutions to deplete the radioactivity to levels below $0.2 \mathrm{~Bq} / \mathrm{L}$ in waste water. One possible remedial solution that could be seriously considered is to treat the water chemically to remove the undesirable radioactive substances by precipitation or sedimentation. This may not prove to be cost-effective, but is an option to be considered.

(iii) Produced waste water and oily sludge that are contaminated by low-levels of natural radioactivity could also pose a significant threat to wildlife [7-9]. Migratory and aquatic birds tend to suffer the most. Accumulation of a thin film of oil on a bird's feathers could lead to ingestion of oil when it preens its feathers. This could subsequently lead to mortality, especially if the oil is radioactive. Abnormally high levels of salts in produced water can also be lethal to birds. Birds are known to die from sodium toxicity. Ingestion of produced water containing low-levels of radioactivity and high sodium levels can lead to chronic effects. Therefore, the dangers of exposure to radioactive contamination cannot be underestimated and suitable measures should be adopted to curb any potential hazard to wildlife. 
(iv) From the perspective of public exposure the hazard is relatively low and within the permissible dose so there is no serious concern for the people who handle and dispose the waste water [12]. However, these workers would be exposed to the low-level radiation, which is cumulative on a continuous basis, and this is undesirable. Genetic damage involving low doses of radiation over an extended period is well documented [8,9], and cannot be ignored.

Clearly, implementation of appropriate remedial measures is necessary. To facilitate the task of remediation it would be useful to monitor water levels at different depths in oil wells to obtain some insight of the function of activity with depth. This could provide information on the origin of the radioactivity and some method could be devised to inhibit activities. Once the produced water is extracted from the oil, one possible remedial measure would be to immobilize the water (after chemical treatment) by storing in vitreous slabs or in underground bunkers. An optional remediation procedure would be to immobilize the wastewater by converting it to a sludge using sand and aggregate, and subsequently constructing concrete blocks for storage in underground bunkers. This will dilute and contain the radioactivity, and enough inert material can be used to confine the exposure to a tolerable level $(<50 \mathrm{~Bq} / \mathrm{kg})$. This exercise can be cost-effective, because sand is plentiful in the desert and any potential threat to the environment is suppressed. The oily sludge could also be converted into concrete blocks and stored in sub-terrestrial caves.

\section{Experimental Section}

\subsection{Sample Collection and Counting}

A total of 90 ground wastewater samples were collected from different sites in the north-western part of the country (Oman) for a period of one year. Samples $(1 \mathrm{~L})$ were prepared for gamma ray counting in standard Marinelli beakers. The detection system consisted of a high-purity germanium detector (20\% relative efficiency) and standard electronics for suppressing unwanted noise (Figure 6). The detector resolution for the gamma rays of interest ranged between 1.2 and $1.7 \mathrm{keV}$, which was considered acceptable [12]. Ambient background was minimized by lead shielding. Sealed radioactive reference sources (Amersham, UK) were used to calibrate the system and validate its performance. Samples were counted overnight (12 hours) to obtain adequate statistics. The ambient background was monitored for an equivalent time. Prior to counting the samples the system was checked for linearity [12].

\subsection{Instrumental Performance}

The gamma-energy spectra of the radionuclides of interest were used to identify them [13]. The most prolific gamma assignments from these radionuclides were considered, i.e., ${ }^{228} \mathrm{Ac}$ : $911 \mathrm{keV}$; ${ }^{226} \mathrm{Ra}$ : $186 \mathrm{keV}$; and ${ }^{40} \mathrm{~K}: 1,461 \mathrm{keV}$. A typical gamma spectrum of ${ }^{228} \mathrm{Ac}$ is shown in Figure 7. The accumulated data represented the sample-specific activity associated with the relevant gamma assignment. The "room background count" showed minimal levels of these radionuclides. Peaks in the spectra that were below the limit of detection $(<1 \mathrm{~Bq} / \mathrm{kg})$ were automatically omitted by the software. Instrument reproducibility was established by counting a single sample six times. The RSD was less 
than $2 \%$, indicating that the reproducibility was acceptable (Table 1 ). The accuracy of the system was validated in terms of relative error by counting sealed standard certified sources [12] and correlating the measured activities with the original certified reference activities. For all measurements the magnitude of the relative error did not exceed 3\%, indicating that the accuracy attained was satisfactory.

Figure 6. The gamma ray detection system.

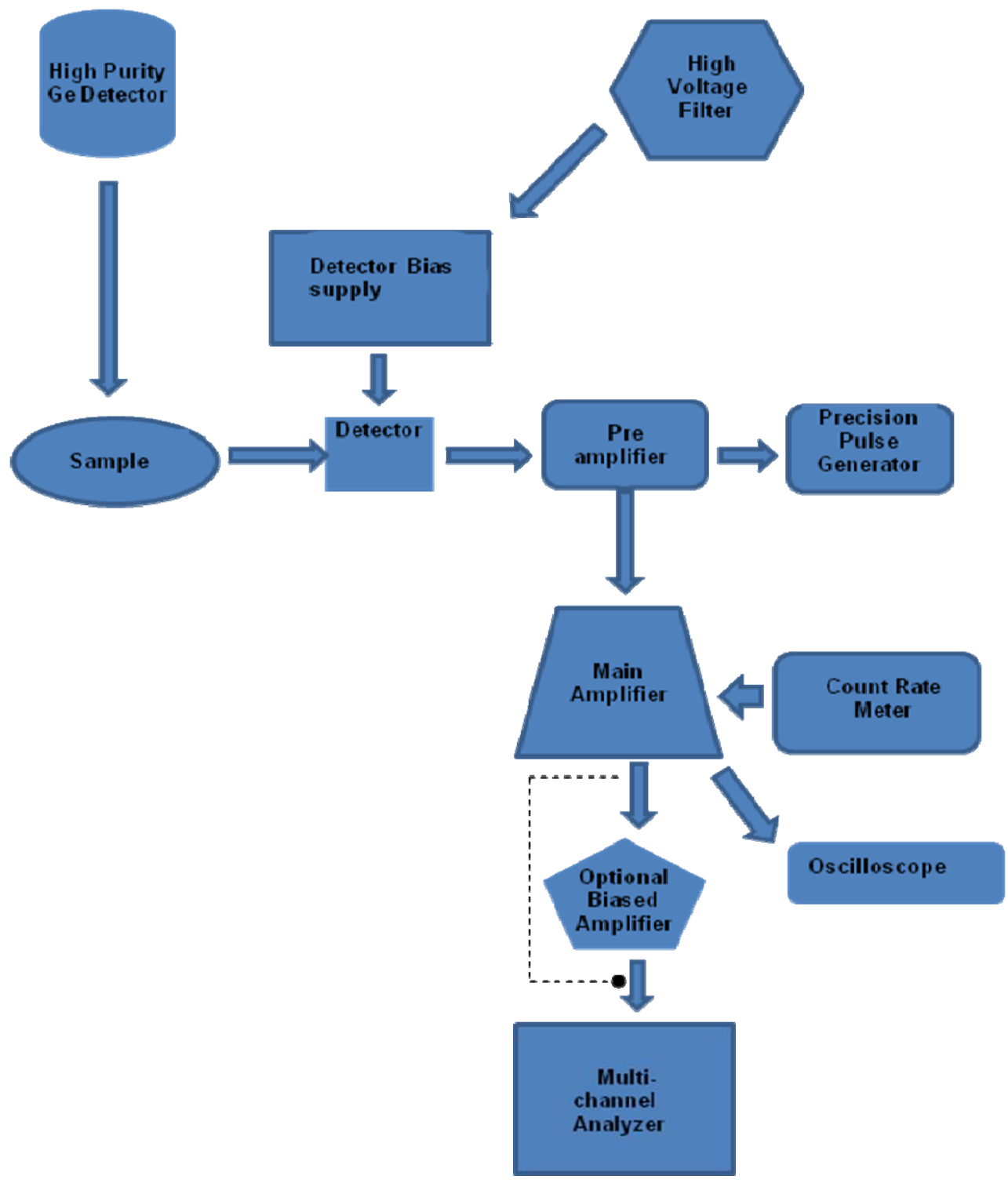


Figure 7. Typical gamma spectrum of actinium-228 showing most intense lines.

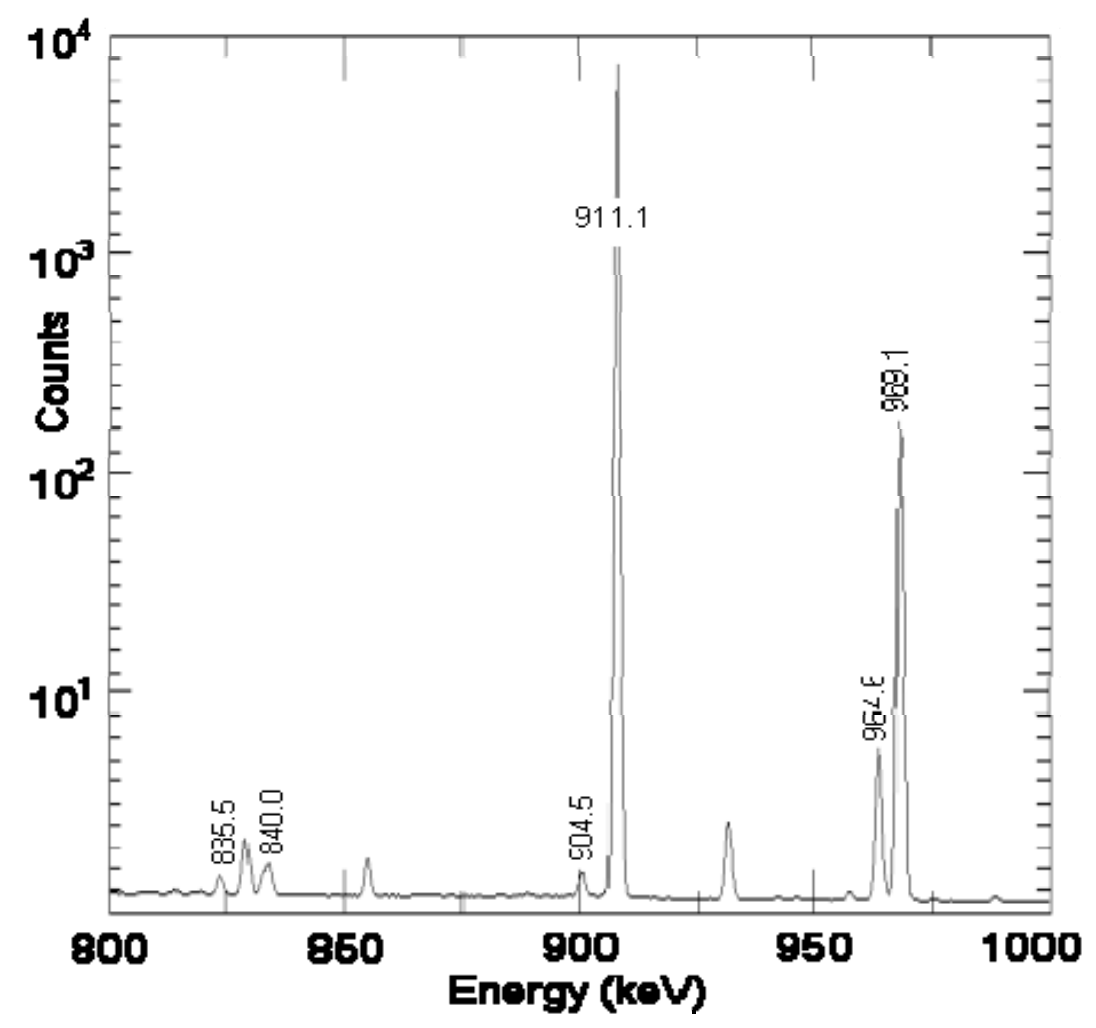

Table 1. Reproducibility measurements (counts/sec) in waste water sample employing the relevant gamma rays from the radionuclides of interest.

\begin{tabular}{cccc}
\hline Measurement & ${ }^{228}$ Ac 911 keV $\boldsymbol{\gamma}$-ray & ${ }^{226} \mathbf{R a} \mathbf{1 8 6 ~ k e V} \boldsymbol{\gamma}$-ray & ${ }^{\mathbf{4 0}} \mathbf{K} \mathbf{1 , 4 6 1} \mathbf{~ k e V} \boldsymbol{\gamma}$-ray \\
\hline 1 & 1,026 & 518 & 1,530 \\
\hline 2 & 1,038 & 529 & 1,527 \\
\hline 3 & 1,019 & 520 & 1,525 \\
\hline 4 & 1,025 & 520 & 1,522 \\
\hline 5 & 1,029 & 514 & 1,535 \\
\hline 6 & 1,040 & 528 & 1,528 \\
\hline Mean \pm RSD & $1,030 \pm 0.78 \%$ & $522 \pm 1.12 \%$ & $1,528 \pm 0.29 \%$ \\
\hline
\end{tabular}

\section{Conclusions}

Our results clearly show that the levels of radioactivity in both the waste water and sludge samples exceed the limits set for drinking water by the US EPA. We conclude that if no remedial steps are implemented, there will be long term risks to the health of the community that relies on recycled water.

\section{Acknowledgements}

The authors thank Sultan Qaboos University, Oman for general assistance and use of their premises. 


\section{References}

1. Al Taie, H.; Pickersgill, J.; Al Taie, N. Oman: A Comprehensive Guide to the Sultanate of Oman; Al Roya Publishers: Muscat, Oman, 1999; pp. 370-372.

2. Barnett, J.; Holbert, K.; Stewart, B.; Hood, W. Lung dose estimates from ${ }^{222}$ Rn in Arizona groundwater based on liquid scintillation measurements. Health Phys. 1995, 68, 699-703.

3. Baggoura, B.; Noureddine, A.; Benkrid, M. Level of natural and artificial radioactivity in Algeria. Appl. Radiat. Isotopes 1998, 49, 867-873.

4. Bou-Rabee, F. Soil radioactivity atlas of Kuwait. Environ. Int. 1997, 23, 5-15.

5. Chang, R. Chemistry; McGraw-Hill: Boston, MA, USA, 2004; pp. 148-153.

6. Chase, R.; Rabinowitz, L. Radioisotope Methodology; Butterworth Scientfic Publications: Philadelphia, PA, USA, 1960; pp. 163-165.

7. De, A.K. Environmental Chemistry; Wiley Eastern Limited: New Delhi, India, 1994; pp. 38-42.

8. Fifield, F.W.; Haines, P.J. Environmental Analytical Chemistry; Blackwell Science: Oxford, UK, 2000; pp. 123-128.

9. Harrison, R.M. Understanding Our Environment; The Royal Society of Chemistry: Cambridge, UK, 1998; pp. 86-93.

10. Manahan, S.E. Environmental Chemistry; Lewis Publishers: Boca Raton, FL, USA, 1994; pp. 183-186.

11. Mango, H. Elevated levels of groundwater radioactivity in southwestern Vermont. In Proceedings of the Annual Denver Meeting, Denver, CO, USA, 7-10 November 2004; pp. 242-248.

12. Salih, F.M.; Pillay, A.E.; Jayasekara, K. ${ }^{7}$ Be levels in sewage sludge: A baseline study. Instrum. Sci. Technol. 2004, 32, 433-444.

13. Faure, G. Principles of Isotope Geology; John Wiley and Sons: New York, NY, USA, 1968; pp. 84-88.

14. De Moraes, M.A; Daltro, T.F.L. Environmental gamma radiation and natural radioactivity in soils in Centro Experimental Aramar (CTMSP-Brazil). Radiat. Prot. Dosimetry 2000, 87, 207-211.

15. Miller, R.L.; Sutcliffe, H., Jr. Occurrence of Natural Radium-226 Radioactivity in Ground Water of Sarasota County, Florida; U.S. Geological Survey Water-Resources Investigations Report 84-4237; U.S. Geological Survey: Denver, CO, USA, 1985; pp. 34-35.

16. Shearman, R. The meaning and ethics of sustainability. Environ. Manage. 1990, 14, 1-8.

17. Robinson, J.G. The limits to caring: sustainable living and the loss to biodiversity. Conserv. Biol. 1993, 7, 20-28.

18. Pillay, A.E.; Williams, J.R.; El Mardi, M.O.; Hassan, S.M.; Al Hamdi, A. Monitoring of Cadmium in “on” and "off” date palms. Environ. Int. 2002, 28, 273-276.

19. Reichenbaugh, R.C. Effects on Ground-Water Quality from Irrigating Pasture with Sewage Effluent Near Lakeland, Florida; U.S. Geological Survey Water-Resources Investigations Report 76-108; U.S. Geological Survey: Denver, CO, USA, 1977; pp.133-138. 
20. Victor, R.; Al-Ujaily, S.R. Water Quality and Management Strategies of Mountain Reservoirs in Arid Northern Oman; Technomic Publishing: Lancaster, UK, 1999; pp. 53-56.

(C) 2010 by the authors; licensee Molecular Diversity Preservation International, Basel, Switzerland. This article is an open-access article distributed under the terms and conditions of the Creative Commons Attribution license (http://creativecommons.org/licenses/by/3.0/). 